\title{
Obesity and its Therapy: A Short Review
}

\author{
Leonardo Napples*, Yun Ching, Stephen Carol Rette and Lovis D'Mello
}

Department of Life Science, Boston Veterans Administration Hospital, Hungary, USA

\begin{abstract}
Weight increase is an understood reaction of treatment with psychotropic medications. Over fifty years prior medications, for example, amitriptyline (Elavil) and lithium were known not connected with significant increments in weight and notwithstanding new eras of psychotropic medications, this unwelcome symptom has held on. The amount of weight is picked up changes however when all is said in one state of mind stabilizers and antipsychotics medications cause more generous weight pick up than antidepressants. Two antipsychotics, clozapine (Clozaril) and olanzapine (Zyprexa) are connected with the best pervasiveness of weight addition; up to $31 \%$ of patients treated with clozapine and $40 \%$ with olanzapine build their weight amid treatment. Some temperament stabilizers, for example, valproate (Depakote) likewise are connected with an also high rate of weight addition. Mirtazapine (Remeron) and paroxetine (Paxil) are two antidepressants with the best weight increase potential among the antidepressants in spite of the fact that aside from buproprion (Wellbutrin) weight addition has been accounted for among the greater part of alternate medications in this classification.
\end{abstract}

Keywords: Obesity; Morbid; Weight

\section{Introduction}

The measure of weight picked up fluctuates relying upon dosage and length of time of treatment. In White, Luthin and Cates 's survey of studies taking a gander at weight pick up with antipsychotic specialists, weight pick up with olanzapine was as high as $9.4 \mathrm{~kg}$ with a normal weight addition of $4.5 \mathrm{~kg}$ [1-3]. Patients picked up by and large 2.3 $\mathrm{kg} / \mathrm{month}$ on olanzapine, $1.7 \mathrm{~kg} / \mathrm{month}$ on clozapine, and $1.8 \mathrm{~kg} /$ month on quetiapine as indicated by studies reported by Akhtar et al. [4]. The state of mind stabilizer, valproic corrosive likewise brought about generous weight pick up; i.e. $5 \mathrm{~kg}$ over a six month treatment period [5]. Treatment with the stimulant mirtazapine was connected with a normal weight increase of $1.74 \mathrm{~kg}$ amid the intense 4-12 week treatment stage and another $2.59 \mathrm{~kg}$ amid the support stage. Comparative measures of weight have been increased amid treatment with paroxetine [4] however this specific medication can possibly bring about significantly more prominent weight pick up. In an examination investigation of weight increase hazard with SSRI treatments, Fava et al. observed that patients taking paroxetine increased more than $7 \%$ of their benchmark weight in around six months [6].

\section{Construction of Body}

The somatotype portrays a specific classification of body construct, decided on the premise of certain physical qualities. Endomorph is an individual having the kind of body fabricate in which tissues got from the endoderm prevail. Endomorphy in which estimations of three skinfold thicknesses (triceps, subscapular, suprailiac) are joined to show the measure of fat in the body. It is redressed for tallness on the grounds that the surface territory volume relationship changes with diet \& stature. Ectomorph is an individual having a kind of body fabricate in which tissues determined with extensive surface region, slim muscles and subcutaneous tissue, and somewhat created digestive viscera, as appeared differently in relation to endomorph. Ectomorph in which estimations of tallness and mass are joined to give a sign of "linearity". A cubic relationship (Ponderal Record) is utilized for the Heath-Carter Anthropometric Somatotype [7].

Mesomorph is an individual having a sort of body fabricate in which tissues got from the mesoderm prevail. There is relative dominance of muscle, bone, and connective tissue, for the most part with substantial, hard build of rectangular layout. This somatotype is arranged between the ectomorph and the endomorph. Mesomorphy in which estimations of bone measurements and muscle outlines (amended for skinfold thickness) are contrasted with the individual's stature with give an evidence of general musculoskeletal improvement. The three parts of the Heath-Carter Anthropometric Somatotype are plotted in two measurements on a cam-molded "chart", called a somatochart. Plotting of the three somatotype parts on a somatochart, and the ordinary grown-up variety is demonstrated as follows.

The focal point of the somatochart is "444" or"333" and speaks to the "unisex ghost", while the base left, endomorphy, corner, is "711", the top, mesomorphy, corner is "171", and the base right, ectomorphy, corner is "117". The run of the mill grown-up male is "353" while the run of the mill grown-up female is "543 (Bailey et al.) demonstrated the accompanying contrasts in somatotype.

In this review concentrate on 181 patients were assessed, 75 of which had an Operation performed. All omentopexies were performed by a solitary specialist. In this way, variability in results is not because of variability in specialized ability of the specialists. Of the 181 sleeve gastrectomies, 40 were performed by 5 different specialists, none of whom perform Operation strategies. What's more, 18 patients had a simultaneous hiatal hernia repair alongside the laparoscopic sleeve gastrectomy [8-12]. The gathering which had the Operation performed was chosen indiscriminately. The patients worked on by specialist an and additionally those worked on by alternate specialists originated from the same overall public and no undeniable contrast in bleakness was noted between the two.

\section{Characteristics of Obesity}

The characteristic recuperating properties of the omentum have

${ }^{*}$ Corresponding author: Leonardo Napples, Department of Life Science, Boston Veterans Administration Hospital, Hungary, USA, Tel: 00768-534-990; E-mail: drleonardonapples@gmail.com

Received September 09, 2015; Accepted September 27, 2015; Published October 02, 2015

Citation: Napples L, Ching Y, Rette SC, D'Mello L (2015) Obesity and its Therapy: A Short Review. J Nutr Disorders Ther 5: 170. doi:10.4172/2161- 0509.1000170

Copyright: $\odot 2015$ Napples L, et al. This is an open-access article distributed under the terms of the Creative Commons Attribution License, which permits unrestricted use, distribution, and reproduction in any medium, provided the original author and source are credited. 
driven us to assess its utilization in diminishing the postoperative complexities of laparoscopic sleeve gastrostomies. We think performing Operation to the staple line will diminish the rate of postoperative inconveniences which are characterized as either a complete hole or a boil, seen on CT sweep or upper GI study. Deficiency may also cause due to this.

Our theory, that Operation to the staple line is connected with a diminished rate of post-agent confusions, was rejected (p-esteem $0.01105,95 \%$ Certainty Interim 0.66 to 55.33 ). Despite what might be expected, it was watched that there was an expanded number of postagent inconveniences in the populace that had an Operation performed (Chances Proportion 6.0571). This is as opposed to the exploration done by Abdo An et al. which observed that Operation added to diminishment in short and long haul grimness [11]. Besides, research done by Afaneh et al. found that Operation did not essentially diminish postoperative nourishment narrow mindedness or GI side effects in beyond husky patients experiencing laparoscopic sleeve gastrectomy [12]. Our discoveries lead us to presume that it is not prescribed to perform Operation as it has not demonstrated to reduction tolerant intricacies. Unexpectedly, it builds agent time under anesthesia which conveys its own particular dangers for the patient and in addition expands the general expense to the healing facility [13]. No adjustment in entanglement rates was seen in patients with a simultaneous hiatal hernia repair. An affiliation is seen between patients in the classes of "super weight" or "extreme corpulence" and difficulties however that affiliation is not found in patients who are beefy beyond belief. This may recommend that Operation is helpful in this gathering. All in all, given the fundamentally higher rate of difficulties in laparoscopic sleeve gastrectomies with Operation contrasted with those without Operation, one can't, in great heart, keep performing omentopexy.

Restrictions of the exploration incorporate the little specimen size and additionally constrained patient populace and comorbidities. Further restrictions incorporate entanglement rates of a solitary specialist performing the omentopexies and additionally the confinements of a review investigation [14].

The aberrant calorimetry has been utilized as an exploration and clinical practice device [10]. As a rule, the product furnished with the accessible calorimeters forms the gathered information and outlines it in reports or spreadsheets containing the estimations of REE, Vo2, Vco2, RQ and others.

\section{Therapies of Obesity}

By the by, here and there the specialist wishes to see how this product figures the previously stated qualities. Once, in the writing, there are disparities among the mathematical statements utilized $[9,11]$, a few challenges emerge right now. Besides, specialists must endeavor to not just depict the qualities given by the calorimeter programming, additionally to report the systems to get it keeping in mind the end goal to guarantee the nature of gathered information. In this way, it is essential to uncover all mathematical statements utilized, how unfaltering state conditions were set up; the standard of the qualities (BTPS or STPD) and under which conditions the test was executed.

The estimation of VE given by the calorimeter and the VI, for this situation, ascertained through Haldane's change are communicated in BTPS. Nonetheless, the estimations of $\mathrm{Vo} 2$ and $\mathrm{Vco} 2$ are typically communicated in STPD, which is the volume of a gas under standard states of temperature $\left(0^{\circ} \mathrm{C}\right)$, barometric weight $(760 \mathrm{mmHg})$ and mugginess (halfway weight of water, $0 \mathrm{mmHg}$ ) [8]. Thusly, it is important to modify the Vo2 and Vco2 to STPD.
Since point by point reports about the estimations identified with circuitous calorimetry are generally not discovered, this paper represents every one of the strides included, subsequent to the courses of action for test execution, the foundation of a relentless state interim, the computations of the estimations of the $V_{0} 2, V_{c o}$, REE and RQ. Also, it accentuates the alteration of qualities to STPD.

The Roux-en-Y Gastric Detour (RYGB) is the best bariatric strategy. Notwithstanding its victories, a developing number of patients who experience RYGB present with clinically noteworthy weight recover in the years taking after their technique. Anatomical etiologies have been regularly involved in this weight recover as either an expansion of the gastric pocket or gastrojejunostomy, or the vicinity of a gastro gastric fistula prompting loss of caloric limitation. Surgical or endoscopic update is a successful intends to address this. Behavioral issues can likewise prompt poor results if patients don't hold fast to strict dietary and way of life regimens taking after their methodology. Poor dietary consistence should be tended to with behavioral and nutritious directing at a multidisciplinary facility. Psychological well-being is a regularly overlooked etiology for weight recidivism. Particularly in high-hazard patients - patients with identity issue and addictions - essentially perceiving the likelihood of psychological wellness issues amid a preoperative appraisal is a decent begins [15]. In conclusion, gut hormone lopsided characteristics including ghrelin and insulin can lead independently to expanded longing and noteworthy hypoglycemia individually, which can hypothetically prompt RYBG disappointment. In any case, more research should be committed to this territory keeping in mind the end goal to be completely alright with making a conclusion. Generally speaking, fruitful techniques for the administration and acknowledgment of weight recidivism taking after RYGB is imperative as these patients make up an essential and developing fragment of any bariatric practice.

The fundamental treatment for anatomical disappointments prompting weight recapture is revisional bariatric surgery, including flexible gastric banding, transformation to biliopancreatic preoccupation duodenal switch, and change to a distal-RYGB [16]. On the other hand, the danger of intricacy of a revisional methodology is higher contrasted and the essential bariatric techniques and the long haul accomplishment of these revisional strategies has yet to be completely illustrated [16].

Revisional methods to oversee anatomic disappointment after RYGB have been performed for a considerable length of time. Most strategies involve surgical re-making of the pocket or stoma utilizing either suture or stapling gadgets. Lamentably, these systems are laden with to a great degree high difficulty and death rates [5]. There are three surgical techniques to oversee weight recidivism post Roux en $Y$ gastric detour. The main alternative involves utilization of a customizable gastric band to the RYGB. This method involves setting a LAGB on the gastric pocket of the RYGB trying to advance more prominent gastric confinement for the patient. A precise audit by Vijgen et al., seven studies with a sum of 94 patients reported further weight reduction, differing from $55.9 \%-94.2 \%$ overabundance body mass file misfortune (EBMIL) following 12-42 months of subsequent [17].

\section{Procedures to Address Psychologic Issues}

Recognizing psychiatric conditions in patients who have had weight recidivism taking after RYGB is a critical component in serving to clarify why the RYGB has fizzled and ought to be executed in preoperative evaluations [18-20]. Patients why should found have malversatile dietary patterns ought to be alluded to behavioral treatment. 
There is proof in the writing that post-agent mediation may be more fruitful than pre-agent intercession for behavioral adjustment. Leahey et al. reported that patients were essentially more inclined to finish behavioral mediation ( $91 \%$ versus $14 \%$ ) after the RYGB has happened as opposed to preceding the operation [21-23].

Stomal consideration: After operation the stomas of all patients were minded via prepared stomal medical attendants in our college surgical unit $[24,25]$. Patients were released from healing facility when an attendant was fulfilled that the patient could fit another machine, could change a pocket without spillage, and could manage minor mischances, for example, stomal spillage, skin abrasion, and unreasonable gas in the stomal pocket.

Quiet qualities, tumor attributes and agent results were looked at between gatherings. These information were acquired from medicinal graphs, operation records and pathology reports. Pathologic discoveries were in view of the sixth TNM grouping [13]. The middle subsequent period was 43 months (go 3-109 months).

The outcomes were communicated as mean \pm standard deviation (SD). The Fisher's careful test was utilized to think about straight out variables and the $t$ test for nonstop variables. A $p$-value $<0.05$ was considered measurably critical standard.

Additionally, laparoscopic surgery has been accounted for as a method with longer operation time when contrasted and routine open surgery. On the other hand, our study demonstrated that there were no noteworthy contrasts between gatherings regarding the mean operation time. We trusted that one of the reasons why the mean operation time was not noteworthy was Lap-APR was portrayed by a lasting stoma and perineal system and in addition Open-APR and the other was that LapAPR could be stayed away from conclusion of the midline laparotomy wound. It was reported that the middle operation time in the Lap-APR was comparable when contrasted and that in the Open-APR bunch in their non-randomized forthcoming similar study. Randomized control study to illuminate the operation time is important [26].

Despite the fact that this study did not uncover huge shortening the length of healing center stay in Lap-APR, most studies have reported that the doctor's facility stay in the laparoscopic surgery for rectal tumor was shorter when contrasted and the traditional open surgery bunch $[14,16,17]$. Lap-APR was described by a changeless stoma and perineal injury and additionally Open-APR. The patients in the LapAPR gathering stayed away from an expansive stomach wound which appeared to give the before recuperation. What's more, our outcomes likewise demonstrated that the patients who experienced Lap-APR could be instructed and accomplish in dealing with their stoma prior in view of no stomach entry point aside from trocar locales and stoma. In spite of the fact that length of postoperative doctor's facility stay was not altogether distinctive between gatherings, we trust that the patients experiencing Lap-APR without an extensive stomach wound can deal with their stoma simpler than those experiencing Open-APR. As far as anyone is concerned, our study was first to elucidate the advantage of Lap-APR as far as stoma consideration [27-30].

\section{Treatment of Morbidity}

In past decades, dietary changes to ward high-starch nourishments (fundamentally sugars), in conjunction with diminishments in physical action because of advanced, innovation driven ways of life, have brought about a scourge of heftiness and its related intricacies [13]. In the United States, Behavioral Danger Variable Reconnaissance Framework (BRFSS) information demonstrated a predominance of weight of $26 \%$ contrasted with National Wellbeing and Nourishment Examination Overview (NHANES) pervasiveness of 35.7\% [31,32].

Broad information have been distributed uncovering falling apart personal satisfaction and psychosocial working as an aftereffect of a wide range of complexities [33-38]. In a meta-examination, Body Mass Index (BMI) classifications were connected with higher all-reason and reason particular mortality; peril proportions (HR) 0.94 for overweight and 1.18 for heftiness all evaluations joined [9]. In the US, grownups with a BMI more prominent than $40 \mathrm{~kg} / \mathrm{m}^{2}$ had a higher danger of death from disease than ordinary weight subjects [10]. In 2008, US restorative expenses equivalent to US\$ 147 billion for each year were ascribed to stoutness and to procurement of consideration of patients with sort II diabetes mellitus and related sequelae $[11,12]$. Comparative results were accounted for from different nations [13].

Weight reduction is the key treatment in patients with heftiness and related entanglements. This weight pandemic warrants anticipation methodologies keeping in mind the end goal to have a quantifiable impact on the populace. These techniques ought to incorporate abnormal state arrangements and facilitated endeavors by governments, associations, groups and people to emphatically impact behavioral change in the public arena. Treatment of stoutness incorporates Way of life Intercession (LI), pharmacotherapy, and bariatric surgery. Advantages of weight reduction on mortality, general prosperity, and other related confusions have been all around reported [8,14-18].

Low calorie diet (LCD): This conventional approach to lose weight restricts calorie intake to $1200 \mathrm{kcal}$ per day while maintaining standard proportions of nutrients to maintain a negative energy balance of $\geq$ $500 \mathrm{kcal} /$ day. Both short-and long-term efficacy of this approach has been well studied and compared with other approaches [29,39]. In a meta-analysis, mean weight loss was $9.8 \pm 4.5 \%$ with mean follow up of 38 weeks [40].

Very low calorie diet (VLCD): A diet containing less than $1000 \mathrm{kcal}$ per day is defined as VLCD. It has been studied and considered safe [41-44]. One study showed sustained beneficial metabolic effects 18 months after a diet of $450 \mathrm{kcal} /$ day for duration of 30 days in severely obese, insulin-treated patients with type 2 diabetes. Mean weight loss was $11.7 \mathrm{~kg}$ in 30 days (10.5\%) [45]. Other studies confirmed similar efficacy and also revealed improvement in visceral, in particular hepatic and subcutaneous, adiposity with reduction in liver volume and size $[44,46]$. This approach has shown some benefit in patients with morbid obesity prior to bariatric surgery in regard to both weight loss and fewer surgical complications [44].

Present thoracic surgery is a restorative claim to fame that has exhibited impressive advancement in the last three or four decades. At first considered a high complex surgery because of the issues of intraoperative anesthesia, of ventilation administration and the troubles in controlling the postoperative period, by the kind of waste that is required. These patients oblige much assets, for example, long stays in concentrated consideration units, long clinic stays, high necessities for absense of pain for post-surgical entry points, which brought therefore less consistence by the patient in his recuperation, in the mechanical ventilatory recovery and expanded occurrence of lung contaminations and twisted diseases in the healing center, which brought about higher patient dismalness and mortality.

The most recent 25 Years have produced numerous innovative advances, quite often got from stomach surgery. The use of innovation from endoscopic surgery in the mid-section has made an upheaval in 
this field. Since procuring the fundamental abilities, a number of the thoracic surgical methods that once in the past obliged methodologies that were exceptionally traumatic, have started to be made with these insignificantly obtrusive strategies.

Since the start of the intra thoracic surgical methodology, it has been important to change the intra thoracic regular Physiology of the lungs for legitimate surgery, which ought to travel through motivation and exhalation.

To counteract lungs caving in, there must be negative weight inside the mid-section, which under ordinary conditions does not permit the lungs to crumple. At the point when this solidness is mutilated by a surgical method and the lung falls, the lung requires the position of waste that imparts the pleural depression to the outside of the body.

By putting a channel into a compartment with fluid, it keeps outside air from re-entering the pleural space, with every breath the lung insufflates and ousts the leftover air that remaining parts in the intra pleural space, liquid from the holder shape an obstruction, known as a water seal.

Ensuing to this water seal, the compartment could adjust to a wellspring of outside suction, which take out removing air from the pleural space quickly.

The advanced thoracic waste has indicated to decrease the times of obliged thoracic seepage and number of days of doctor's facility stay, their caution frameworks give quiet wellbeing and are more successful than routine gadgets. Incorporated suction limit and give battery selfrule to a few hours. Computerized thoracic seepage gadgets permit the patient early ambulation and speedier recovery. In quite chose patients, it is conceivable to send them home with the computerized waste without unfavorably influencing the wellbeing of the patient. In spite of the fact that there are no particular money saving advantage mulls over that show that the employments of the computerized seepages are more monetary when contrasted with ordinary depletes, the decrease long of days of patient hospitalization proposes that this is so

Absolutely concentrates on that are in progress with more cases and new lines of examination, notwithstanding specialized enhancements will be executed to the current advanced gadgets which will yield results in the coming years demonstrating more prominent value of these channels.

This study is intended to inspect the synthetic sythesis and the in vitro cancer prevention agent movement of the unpredictable oil and the concentrates (polar and non-polar sub-divisions) of the methanol concentrate of Olea europea L. (cv) chetoui. GC and GCMS examinations of the unpredictable oil from the dried leaves of the mixture chetoui brought about the distinguishing proof of 32 mixes, speaking to $92.1 \%$ of the oil; alcohols (39.5\%), aldehydes (19.1\%) and ketones (12.2\%) were the primary gatherings of volatiles in the considered cultivar, containing $70.8 \%$ of the aggregate oil. Cell reinforcement exercises of the examples were dictated by the test framework in particular DPPH. The weakest radical rummaging action was displayed by the unstable oil (49.92\%). Cancer prevention agent movement of the non-polar sub-portion of methanol concentrate was better than the all specimens tried with a hindrance of the free radical DPPH estimation of $64.31 \%$. Absolute phenolic substance of the polar and non-polar sub-parts was 65.35 and $69.17 \mathrm{mg} / 100 \mathrm{~g}$ DW, individually [46]. Truth be told, the outcomes demonstrated no noteworthy contrasts in the levels of polyphenols between sub-parts of the methanol concentrate of Olea europea L. Besides, the measure of the aggregate orthodiphenols was most astounding in the non-polar sub-division (219.66 mg/100 g DW).

\section{Acknowledgement}

I would like to thanks to my whole team during the complete review process and my literature work.

\section{Conflict of Interest}

Authors have no conflict of interest.

\section{References}

1. Townsend CM, Sabiston DC (2004) Sabiston textbook of surgery: The biological basis of modern surgical practice. Philadelphia: Saunders.

2. Chandra A, Srivastava RK, Kashyap MP, Kumar R, Srivastava RN, et al. (2011) The anti-inflammatory and antibacterial basis of human omental defense: selective expression of cytokines and antimicrobial peptides. PLoS One 6 : e20446.

3. Campbell BG (2009) Harnessing the Healing Properties of the Omentum Washington State University. ACVSc College Science Week.

4. Bertleff MJ, Lange JF (2010) Perforated peptic ulcer disease: a review of history and treatment. Dig Surg 27: 161-169.

5. Nicolau AE, Merlan V, Veste V, Micu B, Beuran M (2008) Laparoscopic suture repair of perforated duodenal peptic ulcer for patients without risk factors. Chirurgia (Bucur) 103: 629-633.

6. Husain M, Khan RN, Rehmani B, Haris H (2011) Omental patch technique for the ileal perforation secondary to typhoid fever. Saudi J Gastroenterol 17 208-211.

7. Wang N, Sparks SR, Bailey LL (1994) Staged repair using omentum for posttraumatic aortoesophageal fistula. Ann ThoracSurg 58: 557-559.

8. Marino M, Snyder B (2007) Two Sides of the Omentum. Vanderbilt Medical Center. Lens: A New Way of Looking at Science.

9. Zhang C, Hou J, Zheng S, Zheng Z, Hu S (2011) Vascularized atrial tissue patch cardiomyoplasty with omentopexy improves cardiac performance after myocardial infarction. Ann ThoracSurg 92: 1435-1442.

10. Miller JD, DeHoyos A (1993) An evaluation of the role of omentopexy and of early perioperative corticosteroid administration in clinical lung transplantation. The University of Toronto and Washington University Lung Transplant Programs. A J ThoracCardiovascSurg 105: 247-252.

11. Abdo A, Averbach A (2014) Omentopexy (OP) in vertical sleeve gastrectomy (VSG) might be associated with reduced short and long term morbidity. Saint Agnes Hospital Dept. of Surgery. SAGES.

12. Afaneh C, Costa R, Pomp A, Dakin G (2014) A prospective randomized controlled trial assessing the efficacy of omentopexy during laparoscopic sleeve gastrectomy in reducing postoperative gastrointestinal symptoms. Surg Endosc.

13. Wong DC, Chung CC, Chan ES, Kwok AS, Tsang WW, et al. (2006) Laparoscopic abdominoperineal resection revisited: are there any healthrelated benefits? A comparative study. Tech Coloproctol 10: 37-42.

14. Fleshman JW, Wexner SD, Anvari M, La Tulippe JF, Birnbaum EH, et al. (1999) Laparoscopic vs. open abdominoperineal resection for cancer. Dis Colon Rectum 42: 930-939.

15. Aziz O, Constantinides V, Tekkis PP, Athanasiou T, Purkayastha S, et al. (2006) Laparoscopic versus open surgery for rectal cancer: a meta-analysis Ann Surg Oncol 13: 413-424

16. Cornish JA, Tilney HS, Heriot AG, Lavery IC, Fazio VW, et al. (2007) A metaanalysis of quality of life for abdominoperineal excision of rectum versus anterior resection for rectal cancer. Ann Surg Oncol 14: 2056-2068.

17. Kang SB, Park JW, Jeong SY (2011) Open versus laparoscopic surgery for mid and low rectal cancer after neoadjuvant chemoradiotherapy (COREAN trial): short-term outcomes of an open-label randomised controlled trial. Lancet Oncol 11: 637-645.

18. Ministry of Health (1998) Food and Nutrition Guidelines for Healthy Adolescents. A background paper. Wellington, New Zealand NHMRC. 2006. Nutrient Reference Values for Australia and New Zealand. 
19. SPARC (2007) Physical activity guidelines for children and young people (ages 5-18).

20. Millennium Institute of Sport \& Health \& Nestle in partnership with the New Zealand Nutrition Foundation. 2008. Be Healthy Be Active.

21. Quittner AL, Buu A, Watrous M, Davis MA (2000) The Cystic Fibrosis Questionnaire: User's Manual.Washington, DC: Cystic Fibrosis Foundation.

22. Modi AC, Quittner AL (2003) Validation of a disease-specific measure of health-related quality of life for children with cystic fibrosis. J Pediatr Psychol 28: $535-545$.

23. Kuczmaarski RJ, Ogden CL, Guo SS, Curtin LR, Roche AF, et al. (2002) 2000 CDC growth charts for the United States: methods and development. Vital Health Stat 11: 1-190.

24. Lai HJ, Shoff SM (2008) Classification of malnutrition in cystic fibrosis: implications for evaluating and benchmarking clinical practice performance. Am J Clin Nutr 88: 161-166.

25. Borowitz D, Baker RD, Stallings $V$ (2002) Consensus report on nutrition for pediatric patients with cystic fibrosis. J Pediatr Gastroenterol Nutr 35: 246-259.

26. Quittner AL, Sawicki GX, McMullen A, Rasouliyan L, Pasta DJ, et al. (2012) Psychometric evaluation of the Cystic Fibrosis Questionnaire-Revised in a national, US sample. Qual Life Res 21: 1267-1278.

27. Abbott J, Hart A, Havermans T, Matossian A, Goldbeck L, et al. (2011) Measuring health-related quality of life in clinical trials in cystic fibrosis. J Cystic Fibrosis 10: S82-S85.

28. Quittner AL, Modi AC, Wainwright C, Otto K, Kirihara J, et al. (2009) Determination of the minimal clinically important difference scores for the Cystic Fibrosis Questionnaire-Revised respiratory symptom scale in two populations of patients with cystic fibrosis and chronic Pseudomonas aeruginosaairway infection. Chest 135: 1610-1618.

29. Cystic Fibrosis Foundation, Borowitz D, Robinson KA, Rosenfeld M, Davis SD, et al. (2009) Cystic Fibrosis Foundation evidence-based guidelines for management of infants with cystic fibrosis. J Pediatr 155: S73-S93.

30. Stallings VA, Stark LJ, Robinson KA, Feranchak AP, Quinton HB (2008) Evidence-based practice recommendations for nutrition-related management of children and adults with cystic fibrosis and pancreatic insufficiency: results of a systematic review. J Am Diet Assoc 108: 832-839.

31. Milla CE (2004) Association of nutritional status and pulmonary function in children with cystic fibrosis. Curr Opin Pulm Med 10: 505-509.

32. Zemel BS, Jawad AF, Simmons S, Stallings V (2000) Longitudinal relationship among growth, nutritional status, and pulmonary function in children with cystic fibrosis: Analysis of the Cystic Fibrosis Foundation National CF Patient Registry. J Pediatr 137: 374-380.

33. Tluczek A, Becker T, Laxova A, Grieve A, Racine Gilles CN, et al. (2011)
Relationships among health-related quality of life, pulmonary health and newborn screening for cystic fibrosis. Chest 140: 170-177.

34. Gee L, Abbott J, Hart A, Conway SP, Etherington C, et al. (2005) Associations between clinical variables and quality of life in adults with cystic fibrosis. J Cystic Fibrosis 4: 59-66.

35. Gee L, Abbott J, Conway SP, Etherington C, Webb AK (2003) Quality of life in cystic fibrosis: the impact of gender, general health perceptions and disease severity. J Cystic Fibrosis 2: 206-213.

36. Sawicki GS, Sellers DE, Robinson WM (2011) Associations between illness perceptions and health-related quality of life in adults with cystic fibrosis. $J$ Psychosomatic Res 70: 161-167.

37. Sawicki GS, Rasouliyan L, McMullen AH, Wagener JS, McColley SA, et al. (2011) Longitudinal assessment of health-related quality of life in an observational cohort of patients with cystic fibrosis. Pediatr Pulmonol 46: 36-44.

38. Simon SL, Duncan CL, Horky SC, Nick TG, Castro MM, et al. (2011) Body satisfaction, nutritional adherence, and quality of life in youth with cystic fibrosis. Pediatr Pulmonol 46: 1085-1092.

39. Wolter J, Seeney S, Bell S, Bowler S, Masel P, et al. (2002) Effect of long term treatment with azithromycin on disease parameters in cystic fibrosis: a randomized tiral. Thorax 57: 212-216.

40. Saiman L, Marshall BC, Mayer-Hamblett N, Burns JL, Quittner AL, et al. (2003) Azithromycin in patients with cystic fibrosis chronically infected with Pseudomonas aeruginosa: a randomized controlled trial. JAMA 290: 17491756.

41. Elkins MR, Robinson M, Rose BR, Harbour C, Moriarty CP, et al. (2006) A controlled trial of long-term inhaled hypertonic saline in patients with cystic fibrosis. N Engl J Med 354: 229-240.

42. Donaldson SH, Bennett WD, Zeman KL, Knowles MR, Tarran R, et al. (2006) Mucus clearance and lung function in cystic fibrosis with hypertonic saline. $\mathrm{N}$ Engl J Med 354: 241-250.

43. Accurso FJ, Rowe SM, Clancy JP, Boyle MP, Dunitz JM, et al. (2010) Effect of VX-770 in persons with cystic fibrosis and the G551D-CFTR mutation. N Engl J Med 363: 1991-2003.

44. Modi AC, Lim CS, Driscoll KA, Piazza-Waggoner C, Quittner AL, et al. (2010) Changes in pediatric health-related quality of life in cystic fibrosis after IV antibiotic treatment for pulmonary exacerbations. J Clin Psychol Med Settings 17: $49-55$.

45. Oermann CM, Retsch-Bogart GZ, Quittner AL, Gibson RL, McCoy KS, et al. An 18-month study of the safety and efficacy of repeated courses of inhaled aztreonam lysine in cystic fibrosis. Pediatr Pulmonol 45: 1121-1134.

46. Fost NC, Farrell PM (1989) A prospective randomized trial of early diagnosis and treatment of cystic fibrosis: a unique ethical dilemma. Clin Res 37: 495500 